\title{
Clinicopathological features and prognostic implications of Raf kinase inhibitor protein downregulation in tongue squamous cell carcinoma
}

\author{
FENGCHUN HU ${ }^{1,2 *}$, XIAOHUA CHEN ${ }^{2,3^{*}}$, XIQIANG LIU ${ }^{1,2}$, CHENG WANG $^{1,2}$, \\ LANHAI $\mathrm{LV}^{2}$, NAN XIE ${ }^{2,3}$, TIANYI WANG ${ }^{4}$ and HONGZHANG HUANG ${ }^{1,2}$
}

${ }^{1}$ Department of Oral Maxillofacial-Head and Neck Oncology, The Affiliated Hospital of Stomatology, Sun Yat-Sen University, Guangzhou, Guangdong 510055; ${ }^{2}$ Guangdong Provincial Key Laboratory of Stomatology, Guangzhou, Guangdong 510080; ${ }^{3}$ Department of Oral Pathology, The Affiliated Hospital of Stomatology, Sun Yat-Sen University, Guangzhou, Guangdong 510055, P.R. China; ${ }^{4}$ Center for Immunology and Infectious Diseases, SRI International, Harrisonburg, VA 22802, USA

Received August 4, 2014; Accepted April 24, 2015

DOI: $10.3892 / 01.2015 .3496$

\begin{abstract}
Raf kinase inhibitor protein (RKIP) is recognized as a suppressor of metastasis, and the downregulation of RKIP is associated with aggressive events and a poor outcome in a variety of solid tumors. However, the clinical relevance of RKIP expression in tongue squamous cell carcinoma (TSCC) remains unclear. In the present study, the expression of RKIP in 85 pairs of TSCC and corresponding adjacent non-cancerous tissues, 30 matched metastatic lesions from the cervical lymph nodes and 32 oral leukoplakia samples were assessed using immunohistochemical methods. The association between RKIP expression and clinicopathological features was then evaluated. Kaplan-Meier survival analysis and Cox proportional hazards model were used to estimate the effect of RKIP expression on the survival time of patients with TSCC. The results revealed that RKIP expression was dramatically downregulated in TSCC, and to an even greater extent in metastatic lesions. RKIP downregulation was significantly associated with the presence of lymphatic metastasis and the clinical stage of TSCC. Furthermore, patients with low RKIP expression demonstrated a significantly shorter overall survival time. Multivariate analysis indicated that RKIP expression may be
\end{abstract}

Correspondence to: Dr Xiqiang Liu or Professor Hongzhang Huang, Department of Oral Maxillofacial-Head and Neck Oncology, The Affiliated Hospital of Stomatology, Sun Yat-Sen University, 56 Lingyuan West Road, Guangzhou, Guangdong 510055, P.R. China E-mail: xiqiangliu@aliyun.com

E-mail: huanghongzhang@tom.com

${ }^{*}$ Contributed equally

Key words: Raf kinase inhibitor protein, tongue squamous cell carcinoma, metastasis, prognosis an independent prognostic factor in TSCC. In conclusion, the present findings indicate that the lack of RKIP expression is of clinical significance and may serve as a prognostic biomarker in TSCC.

\section{Introduction}

Tongue squamous cell carcinoma (TSCC) is the most common type of oral cancer. According to data released by the American Cancer Society, an estimated 13,590 novel TSCC cases were predicted to occur in the USA in 2014, accounting for one-third of all oral cavity and pharynx cancers (1). TSCC tends to demonstrate more aggressive behavior, including a high frequency of local invasion and regional lymph node metastasis (2). Consequently, the mortality rate for TSCC continues to be high, with a typical overall five-year survival rate of $<50 \%$ (3). In order to delineate the clinical behavior of TSCC and to personalize therapy, the identification of novel biomarkers for tumor aggressiveness is required.

Raf kinase inhibitor protein (RKIP) is a member of the phosphatidylethanolamine-binding protein family. RKIP was original identified as a physiological inhibitor of the Raf/mitogen-activated protein/extracellular signal-regulated kinase $($ ERK) kinase $(\mathrm{MEK}) / \mathrm{ERK}$ pathway $(4,5)$ and appears to be implicated in a variety of intracellular signaling pathways (6-8) that control cell proliferation (9), differentiation (10), adhesion (11) and epithelial-mesenchymal transition (12). RKIP has also been implicated in tumor progression. It was suggested that RKIP acts as a metastasis suppressor in a variety of malignancies, including prostate (13), breast (14), hepatocellular (15), colorectal (16) and gastric cancers (17). These previous findings prompted the elucidation of the clinicopathological features and implications of RKIP expression in patients with TSCC. Therefore, the present study investigated the protein levels of RKIP in non-cancerous and tumor tissues, and assessed the role of RKIP in the clinical outcome of the patients with TSCC. 
Table I. Association between RKIP expression and clinicopathological features in patients with tongue squamous cell carcinoma.

\begin{tabular}{|c|c|c|c|c|}
\hline \multirow[b]{2}{*}{ Clinicopathological features } & \multirow[b]{2}{*}{ Patients, $\mathrm{n}$} & \multicolumn{2}{|c|}{ RKIP expression, $\mathrm{n}(\%)$} & \multirow[b]{2}{*}{ P-value } \\
\hline & & High & Low & \\
\hline \multicolumn{5}{|l|}{ Gender } \\
\hline Male & 51 & $19(37.3)$ & $32(62.7)$ & \multirow[t]{2}{*}{0.153} \\
\hline Female & 34 & $18(52.9)$ & $16(47.1)$ & \\
\hline \multicolumn{5}{|l|}{ Age, years } \\
\hline$\geq 55$ & 40 & $16(40.0)$ & $24(60.0)$ & \multirow[t]{2}{*}{0.536} \\
\hline$<55$ & 45 & $21(46.7)$ & $24(53.3)$ & \\
\hline \multicolumn{5}{|l|}{ Differentiation } \\
\hline Well & 49 & $23(46.9)$ & $26(53.1)$ & \multirow[t]{2}{*}{0.460} \\
\hline Moderately or poorly & 36 & $14(38.9)$ & $22(61.1)$ & \\
\hline \multicolumn{5}{|l|}{ pT stage } \\
\hline $\mathrm{T} 1-2$ & 66 & $31(47.0)$ & $35(53.0)$ & \multirow[t]{2}{*}{0.233} \\
\hline T3-4 & 19 & $6(31.6)$ & $13(68.4)$ & \\
\hline \multicolumn{5}{|l|}{ pN stage } \\
\hline No & 55 & $29(52.7)$ & $26(47.3)$ & \multirow[t]{2}{*}{0.021} \\
\hline $\mathrm{N}+$ & 30 & $8(26.7)$ & $22(73.3)$ & \\
\hline \multicolumn{5}{|l|}{ pTNM stage } \\
\hline I-II & 45 & $25(55.6)$ & $20(44.4)$ & \multirow[t]{2}{*}{0.018} \\
\hline III-IV & 40 & $12(30.0)$ & $28(70.0)$ & \\
\hline
\end{tabular}

aP-value of $\chi^{2}$ test is shown. pTNM stage, pathological tumor-node-metastasis stage; RKIP, Raf kinase inhibitor protein.

\section{Materials and methods}

Patients and tissue samples. All tissue samples were obtained from the Affiliated Hospital of Stomatology, Sun Yat-Sen University (Guangzhou, China) between January 2007 and December 2012. In total, 85 pairs of paraffin-embedded tissue samples from patients with TSCC, consisting of TSCC tissue and adjacent non-cancerous tissues, were assessed. An additional 32 oral leukoplakia lesions were also analyzed (Table I). In patients that demonstrated lymph node involvement $(n=30)$, the corresponding lymph node metastases were also examined. The specimens were obtained from the patients subsequent to radical surgery, with informed consent being obtained from all patients for the use of the surgically-resected specimens for research purposes, according to the guidelines for research on human tissues and samples set by the Institution Review Board of Sun Yat-Sen University. No patients received any form of adjuvant therapy prior to surgery. All histopathological diagnoses were based on the Union for International Cancer Control or the 2002 American Joint Committee on Cancer criteria (18), and the diagnoses were reviewed by two experienced pathologists.

Immunohistochemistry. Formalin-fixed, paraffin-embedded tissue sections were subjected to immunohistochemical analysis. The 4- $\mu \mathrm{m}$ tissue sections were routinely dewaxed, rehydrated and blocked using $0.3 \%$ hydrogen peroxide in methanol for $30 \mathrm{~min}$ at room temperature. Antigen retrieval was performed using $10 \mathrm{mM}$ sodium citrate buffer $(\mathrm{pH} \mathrm{6.0)}$ at $95^{\circ} \mathrm{C}$ for $20 \mathrm{~min}$. To reduce non-specific binding, the slides were blocked with $10 \%$ goat serum for $30 \mathrm{~min}$ at room temperature. The tissue sections were incubated in a humidified chamber at $4^{\circ} \mathrm{C}$ overnight with a primary polyclonal $\mathrm{IgG}$ rabbit anti-human RKIP antibody (dilution, 1:100; catalog no. sc-28837; Santa Cruz Biotechnology, Inc., Santa Cruz, CA, USA). Subsequent to washing three times in phosphate-buffered saline (PBS), the slides were incubated with horseradish peroxidase and visualized with diaminobenzidine (DAKO Deutschland GmbH, Hamburg, Germany), and the slides were counterstained with hematoxylin. To confirm the specificity of the immunostaining, a negative control was included in each run by substituting PBS for the primary antibody.

Evaluation of immunohistochemical staining. Five random fields of each section were viewed under a light microscope (Axioskop 40; Zeiss, Oberkochen, Germany) at x400 magnification. The sections were independently examined and scored by three investigators, who were blind to the clinical features and outcomes of the cases. The expression of RKIP was scored by multiplication of the average signal intensity, which was scored on a scale of $0-3$, and percentage of positively stained tumor cells, which was scored on a scale of $0-4$, as previously described (18). The final immunoreactive score reported is the average of the scores from the three investigators. Receiver operating characteristic (ROC) analysis resulted in tissues with a final score $>4$ being classified as demonstrating high RKIP expression (sensitivity, $81.5 \%$; specificity, 93.7\%). The tissues that obtained a score $\leq 4$ were classified as demonstrating low RKIP expression. 

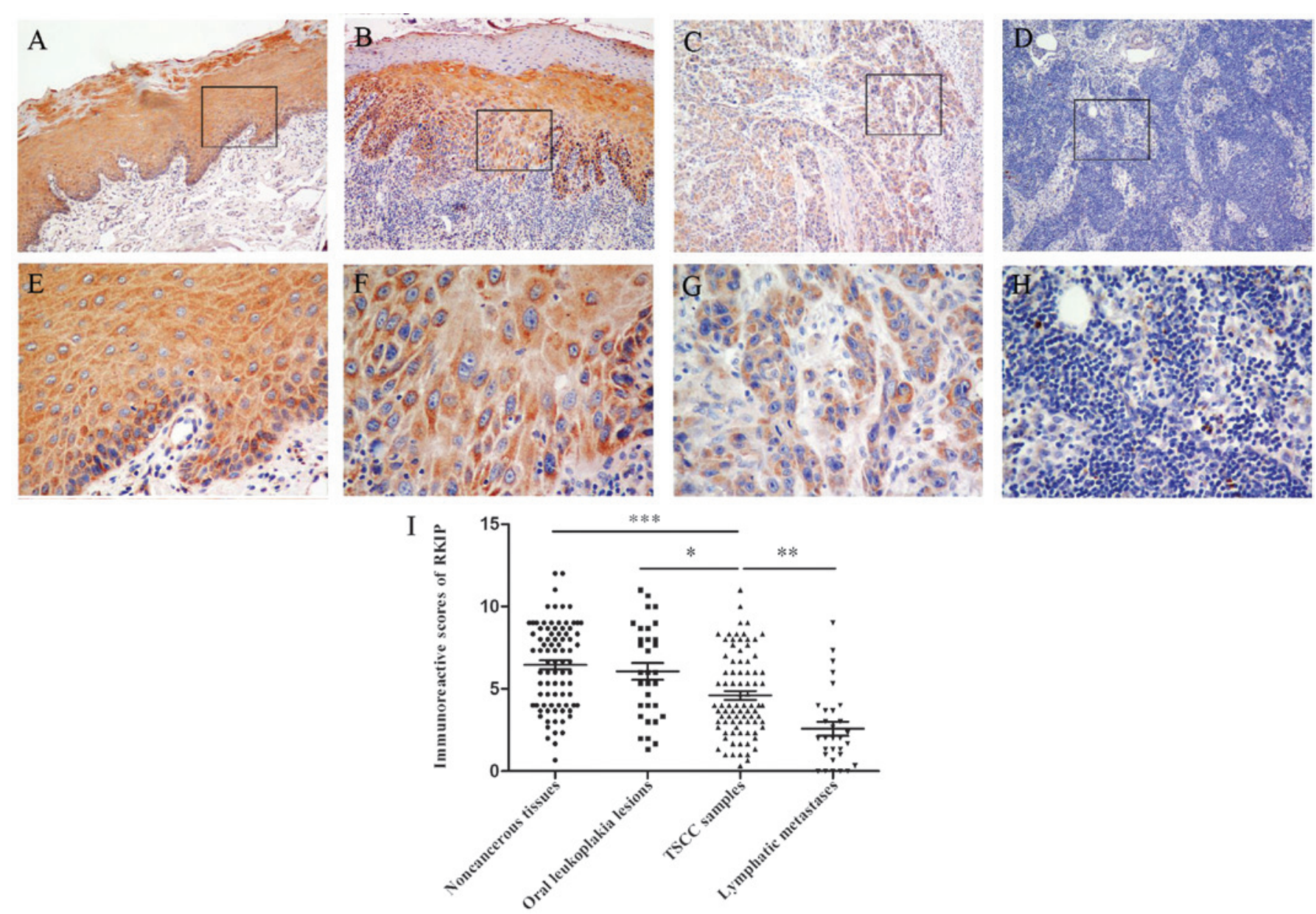

Figure 1. Expression of RKIP in TSCC tissues. (A) Strong RKIP staining in non-cancerous tongue tissue adjacent to TSCC. (B) Positive RKIP staining in oral leukoplakia sample. (C) Moderate RKIP staining in a TSCC tissue sample. (D) Absence of RKIP staining in matched metastatic lesions. (A-D) Magnification, x100. (E-H) Increased magnification of the rectangles in A-D, respectively. Magnification, x200. (I) A vertical scatter plot was depicted to demonstrate the relative expression level of RKIP in various tissues. RKIP, Raf kinase inhibitor protein; TSCC, tongue squamous cell carcinoma.

Statistical analysis. All statistical analyses were performed using SPSS 18.0 software (SPSS, Inc., Chicago, IL, USA). The association between RKIP expression and clinicopathological parameters was determined using the $\chi^{2}$ test. Survival was evaluated using the Kaplan-Meier method, and the statistical significance of the differences between the survival of patients was examined using the Log-rank test. Analysis of the association between the survival time and the clinicopathological variables was performed by univariate and multivariate analyses using a Cox regression. $\mathrm{P}<0.05$ was considered to indicate a statistically significant difference.

\section{Results}

Patient characteristics. The clinicopathological characteristics of the patients are summarized in Table I. The patients consisted of 51 males and 34 females, with a median age of 54 years (range, 22-82-years). Post-operative pathological tumor-node-metastasis (pTNM) staging evaluation revealed stage I disease in 15 patients, stage II disease in 30 patients, stage III disease in 22 patients and stage IV disease in 18 patients. The histopathological diagnoses consisted of well-differentiated TSCC in 49 patients $(57.6 \%)$, moderately differentiated TSCC in 30 patients (35.3\%) and poorly differentiated TSCC in 6 patients (7.1\%). The median follow-up time was 39 months (range, 4-83 months) and 37.6\% (32/85) of patients had succumbed to TSCC at the time of the final follow-up.

Pattern of RKIP expression in TSCC and association with clinicopathological parameters. In non-cancerous tissues adjacent to TSCC and oral leukoplakia lesions, RKIP was detected in almost all the layers of the epithelia, and was mainly expressed in the cytoplasm. In TSCC samples, RKIP was also predominantly detected in the cytoplasm, and sporadic nuclear staining was also found. Overall, $43.5 \%$ (37/85) of the primary tumor tissues demonstrated high RKIP expression, while 71.8\% $(61 / 85)$ of the corresponding adjacent non-cancerous tissues and $65.6 \%(21 / 32)$ of the oral leukoplakia lesions demonstrated high RKIP expression (Table II). There was no statistically significant difference between RKIP expression in adjacent non-cancerous tissues and oral leukoplakia lesions $(\mathrm{P}=0.518)$. However, a significant decrease in RKIP expression was noted in TSCC samples compared with either adjacent non-cancerous tissues $(\mathrm{P}=0.000)$ or oral leukoplakia lesions $(\mathrm{P}=0.033)$.

In order to evaluate the role of RKIP in TSCC, the association between RKIP expression and any of the clinicopathological parameters was investigated (Table I). The results 
Table II. RKIP expression level in TSCCs and related tissues.

\begin{tabular}{lcrr}
\hline & & \multicolumn{2}{c}{ RKIP expression, $\mathrm{n}(\%)$} \\
\cline { 3 - 4 } Tissue type & Patients, $\mathrm{n}$ & High & Low \\
\hline Adjacent non-cancerous tissue & 85 & $61(71.8)$ & $24(28.2)$ \\
TSCC tissue & 85 & $37(43.5)$ & $48(56.5)$ \\
Oral leukoplakia lesions & 32 & $21(65.6)$ & $11(34.4)$ \\
Lymph node metastases & 30 & $5(16.7)$ & $25(83.3)$ \\
\hline
\end{tabular}

RKIP, Raf kinase inhibitor protein; TSCC, tongue squamous cell carcinoma.

Table III. Cox proportional hazards model analysis of variables affecting survival in patients with tongue squamous cell carcinoma.

\begin{tabular}{|c|c|c|c|c|c|}
\hline \multirow[b]{2}{*}{ Variable } & \multirow[b]{2}{*}{ Comparison } & \multicolumn{2}{|c|}{ Univariate analysis } & \multicolumn{2}{|c|}{ Multivariate analysis } \\
\hline & & $\mathrm{HR}(95 \% \mathrm{CI})$ & P-value & $\mathrm{HR}(95 \% \mathrm{CI})$ & P-value \\
\hline Gender & Male vs. female & $0.693(0.333-1.445)$ & 0.328 & & \\
\hline Age & $\geq 55$ years vs. $<55$ years & $1.104(0.549-2.219)$ & 0.781 & & \\
\hline Differentiation & Well vs. moderately or poorly & $1.727(0.858-3.475)$ & 0.126 & & \\
\hline pT stage & T1-2 vs. T3-4 & $0.811(0.350-1.890)$ & 0.625 & & \\
\hline pN stage & $\mathrm{N}^{0}$ vs. $\mathrm{N}^{+}$ & $2.261(1.127-4.539)$ & 0.022 & $1.512(0.503-4.546)$ & 0.462 \\
\hline pTNM stage & I-II vs. III-IV & $2.135(1.041-4.380)$ & 0.038 & $1.286(0.412-4.011)$ & 0.665 \\
\hline RKIP expression & High vs. low & 3.015 (1.299-6.999) & 0.010 & $2.567(1.083-6.083)$ & 0.032 \\
\hline
\end{tabular}

pTNM stage, pathological tumor-node-metastasis stage; RKIP, Raf kinase inhibitor protein; HR, hazard ratio; CI, confidence interval.

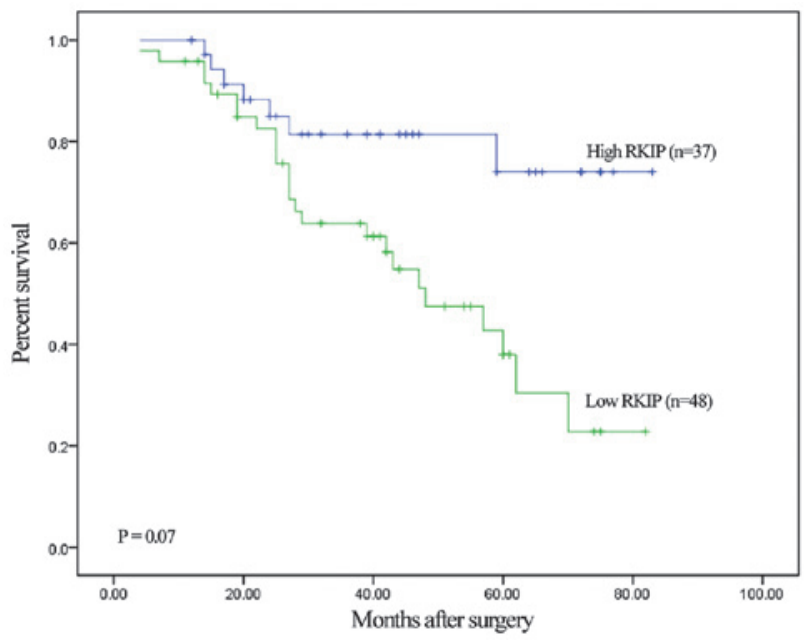

Figure 2. Keplan-Meier survival analysis for patients with TSCC. The P-value was determined using the log-rank test. Survival time was calculated based on the date of surgery and the last follow-up. Comparison of the overall survival between TSCC patients with low RKIP and high RKIP expression tumors. RKIP, Raf kinase inhibitor protein; TSCC, tongue squamous cell carcinoma.

revealed that RKIP expression was significantly associated with the $p N$ stage $(\mathrm{P}=0.021)$ and pTNM stage $(\mathrm{P}=0.018)$. No significant association was identified between RKIP expression and gender $(\mathrm{P}=0.153)$, age $(\mathrm{P}=0.536)$, tumor differentiation $(\mathrm{P}=0.460)$ and $\mathrm{pT}$ stage $(\mathrm{P}=0.233)$.

Loss of RKIP in lymph node metastases. RKIP expression was considerably less frequent in patients with lymph node involvement $(26.7 \% ; 8 / 30)$ compared with patients without node involvement $(52.7 \%$; 29/55). In addition, RKIP expression was less frequent in the corresponding lymph node metastases $(16.7 \% ; 5 / 30)$ compared with the primary TSCC tissues $(\mathrm{P}=0.009)$. Notably, 5 of the metastases demonstrating low RKIP expression completely lacked RKIP expression, obtaining an immunoreactive score of 0 (Fig. 1D and H).

Association between RKIP expression and survival in TSCC patients. To investigate the association between RKIP expression and the clinical outcome of TSCC patients, the association between the survival status and RKIP expression of patients was analyzed. The results revealed that patients possessing a TSCC tumor with low RKIP expression demonstrated a significantly worse prognosis compared with patients that possessed a tumor with high RKIP expression ( $\mathrm{P}=0.007$; Fig. 2). The mean survival time of patients with low RKIP expression $(n=37)$ was 44.1 months, while the mean survival time of the patients with high RKIP expression $(n=48)$ was 30.3 months.

To further assess whether RKIP expression is a prognostic parameter in patients with TSCC, regression analysis using a Cox proportional hazards model was performed. The covariate 
parameters included several clinicopathological variables in addition to RKIP, as reported in Table III. In univariate analysis, low RKIP expression, lymph node involvement and pTNM stage III or IV lesions demonstrated a significantly increased hazard ratio (HR) for poor prognosis. In addition, multivariate analysis was performed using variables that demonstrated a significantly increased HR in univariate analysis. The results of multivariate analysis revealed that RKIP expression was the only independent prognostic predictor of TSCC outcome $(\mathrm{P}=0.032$; Table III). These results strongly indicated that the downregulated RKIP expression in TSCC patients is closely associated with a poor prognosis.

\section{Discussion}

RKIP plays an important role in cell growth (9), mitosis (19), motility (20) and apoptosis (21) by regulating multiple intracellular signaling pathways, including the Raf/MEK/ERK pathway $(4,5)$, nuclear factor- $\kappa \mathrm{B}$ pathway $(6)$, G-protein coupled receptor signaling cascade $(7,8)$ and glycogen synthase kinase-3 $\beta / \beta$-catenin pathway (22). Previous studies have revealed that RKIP acts as a tumor suppressor and suppressor of metastasis in a variety of malignancies (13-17). However, little is known about the function of RKIP in oral cancer, and particularly in TSCC. The present study observed that RKIP was intensively expressed in non-cancerous and pre-cancerous tongue tissues. This result is consistent with a previous study that reported a high rate $(85.7 \%)$ of RKIP immunostaining in normal tissue of the head and neck, consisting of tissues from the tongue, lip, mouth, larynx and pharynx (16). By contrast, the present study found that RKIP expression is markedly reduced in human TSCC tissues. Notably, the level of RKIP expression was found to be even lower in the matched tissues from lymph node metastasis. Loss of RKIP expression was also found to be significantly associated with the presence of lymphatic metastasis and advanced clinical stage. This finding is consistent with the reported association between the reduction of RKIP and tumor progression and metastasis in numerous other cancers. However, the present study found no significant association between RKIP expression and tumor size or histological grade in patients with TSCC. These results indicate that although RKIP affects progression and metastasis, it does not have an influence on the tumorigenic properties of TSCC. Similarly, previous studies have reported that RKIP expression is not associated with tumor size or histological grade in breast cancer (14). In addition, the restoration of RKIP expression has been reported to suppress invasion and lung metastasis in prostate cancer, but not tumor growth (13). Thus, the present results suggest that RKIP may function as a suppressor of metastasis in TSCC.

Furthermore, the loss of RKIP expression is associated with a poor prognosis in prostate (23), gastric (24), pancreatic (25), and bladder cancers (26) and glioma (27). In the present study, well-established prognostic markers, such as lymph node metastasis and an advanced pTNM stage, were significantly associated with patient survival time. The present study revealed that reduced cytoplasmic expression of RKIP, which was found in $56.5 \%$ of the tissues, is significantly associated with a shorter overall survival time in patients with TSCC. In addition, a trend was observed between the loss of
RKIP expression and the presence of metastasis. Accordingly, patients with positive lymphatic metastases demonstrated relatively lower RKIP expression compared with the patients without metastases. Although the mechanistic basis for these subset differences is not known, the identification of these differences may aid in future tailored therapy and early prediction of the survival time of patients with TSCC. Additional studies with larger cohorts are required to validate the role of RKIP as a prognostic marker in TSCC.

To the best of our knowledge, the current study is the first study that has analyzed RKIP expression in TSCC to be reported in the literature. The expression level of RKIP was also assessed in the metastatic lymph node lesions of TSCC. The present results revealed that loss of RKIP expression was significantly associated with tumor progression and metastasis. Despite the importance of RKIP in tumor progression and the development of metastasis, the mechanism of RKIP downregulation remains largely unknown. Previous studies have investigated the $\mathrm{CpG}$ methylation status of the RKIP promoter in human cancers as a possible mechanism for the downregulation $(28,29)$, but the results are inconsistent and may not completely explain the loss of RKIP expression in malignancies. Future studies evaluating the possible mechanisms of RKIP downregulation in TSCC may be required.

The present study reports that RKIP expression is lost during TSCC progression, and in particular, is absent in lymph node metastases. The current study presents evidence that the loss of RKIP expression in TSCC is associated with the clinicopathological characteristics of cancer aggressiveness. Notably, loss of RKIP expression is associated with poor survival time and may act as a potential biomarker of poor prognosis in TSCC patients. Additional studies in larger series and with in vitro and in vivo models are required to assess the role of RKIP expression in the tumor progression, metastasis and survival of TSCC patients.

\section{Acknowledgements}

This study was supported by the National Natural Science Foundation of China (grant nos. 81172567, 81272949, 81202136 and 81372885), Program for New Century Excellent Talent in University, Ministry of Education, China (grant no. NCET-11-0535) and the Fundamental Research Funds for the Central Universities (grant no. 12ykpy69).

\section{References}

1. Siegel R, Ma J, Zou Z and Jemal A: Cancer statistics, 2014. CA Cancer J Clin 64: 9-29, 2014.

2. Yuasa-Nakagawa K, Shibuya H, Yoshimura R, Miura M, Watanabe H, Kishimoto S and Omura K: Cervical lymph node metastasis from early-stage squamous cell carcinoma of the oral tongue. Acta Otolaryngol 133: 544-551, 2013.

3. Hauswald H, Zwicker F, Rochet N, Jensen AD, Debus J and Lindel K: Treatment of squamous cell carcinoma of the mobile tongue or tongue margins: An interdisciplinary challenge. Acta Oncol 52: 1017-1021, 2013.

4. Yeung K, Seitz T, Li S, Janosch P, McFerran B, Kaiser C, Fee F, Katsanakis KD, Rose DW, Mischak H, et al: Suppression of Raf-1 kinase activity and MAP kinase signalling by RKIP. Nature 401: 173-177, 1999.

5. Yeung K, Janosch P, McFerran B, Rose DW, Mischak H, Sedivy JM and Kolch W: Mechanism of suppression of the Raf/MEK/extracellular signal-regulated kinase pathway by the raf kinase inhibitor protein. Mol Cell Biol 20: 3079-3085, 2000. 
6. Yeung KC, Rose DW, Dhillon AS, Yaros D, Gustafsson M Chatterjee D, McFerran B, Wyche J, Kolch W and Sedivy JM: Raf kinase inhibitor protein interacts with NF-kappaB-inducing kinase and TAK1 and inhibits NF-kappaB activation. Mol Cell Biol 21: 7207-7217, 2001.

7. Corbit KC, Trakul N, Eves EM, Diaz B, Marshall M and Rosner MR: Activation of Raf-1 signaling by protein kinase $C$ through a mechanism involving Raf kinase inhibitory protein. J Biol Chem 278: 13061-13068, 2003.

8. Lorenz K, Lohse MJ and Quitterer U: Protein kinase C switches the Raf kinase inhibitor from Raf-1 to GRK-2. Nature 426: 574-579, 2003.

9. Zhang L, Fu Z, Binkley C, Giordano T, Burant CF, Logsdon CD and Simeone DM: Raf kinase inhibitory protein inhibits beta-cell proliferation. Surgery 136: 708-715, 2004.

10. Schuierer MM, Heilmeier U, Boettcher A, Ugocsai P, Bosserhoff AK, Schmitz G and Langmann T: Induction of Raf kinase inhibitor protein contributes to macrophage differentiation. Biochem Biophys Res Commun 342: 1083-1087, 2006.

11. Mc Henry KT, Montesano R, Zhu S, Beshir AB, Tang HH, Yeung KC and Fenteany G: Raf kinase inhibitor protein positively regulates cell-substratum adhesion while negatively regulating cell-cell adhesion. J Cell Biochem 103: 972-985, 2008.

12. Shin SY, Rath O, Zebisch A, Choo SM, Kolch W and Cho KH Functional roles of multiple feedback loops in extracellular signal-regulated kinase and Wnt signaling pathways that regulate epithelial-mesenchymal transition. Cancer Res 70: 6715-6724, 2010

13. Fu Z, Smith PC, Zhang L, Rubin MA, Dunn RL, Yao Z and Keller ET: Effects of raf kinase inhibitor protein expression on suppression of prostate cancer metastasis. J Natl Cancer Inst 95: $878-889,2003$

14. Hagan S, Al-Mulla F, Mallon E, Oien K, Ferrier R, Gusterson B, García JJ and Kolch W: Reduction of Raf-1 kinase inhibitor protein expression correlates with breast cancer metastasis. Clin Cancer Res 11: 7392-7397, 2005.

15. Schuierer MM, Bataille F, Weiss TS, Hellerbrand C and Bosserhoff AK: Raf kinase inhibitor protein is downregulated in hepatocellular carcinoma. Oncol Rep 16: 451-456, 2006.

16. Al-Mulla F, Hagan S, Behbehani AI, Bitar MS, George SS, Going JJ, García JJ, Scott L, Fyfe N, Murray GI and Kolch W.: Raf kinase inhibitor protein expression in a survival analysis of colorectal cancer patients. J Clin Oncol 24: 5672-5679, 2006.

17. Chatterjee D, Sabo E, Tavares R and Resnick MB: Inverse association between Raf Kinase Inhibitory Protein and signal transducers and activators of transcription 3 expression in gastric adenocarcinoma patients: Implications for clinical outcome. Clin Cancer Res 14: 2994-3001, 2008.
18. Wang C, Liu X, Huang H, Ma H, Cai W, Hou J, Huang L, Dai Y, Yu T and Zhou X: Deregulation of Snai2 is associated with metastasis and poor prognosis in tongue squamous cell carcinoma. Int J Cancer 130: 2249-2258, 2012

19. Eves EM, Shapiro P, Naik K, Klein UR, Trakul N and Rosner MR: Raf kinase inhibitory protein regulates aurora B kinase and the spindle checkpoint. Mol Cell 23: 561-574, 2006.

20. Bement WM: A role for RKIP in cell motility. Chem Biol 12: 953-954, 2005.

21. Odabaei G, Chatterjee D, Jazirehi AR, Goodglick L, Yeung K and Bonavida B: Raf-1 kinase inhibitor protein: Structure, function, regulation of cell signaling and pivotal role in apoptosis. Adv Cancer Res 91: 169-200, 2004

22. Al-Mulla F, Bitar MS, Al-Maghrebi M, Behbehani AI, Al-Ali W, Rath O, Doyle B, Tan KY, Pitt A and Kolch W: Raf kinase inhibitor protein RKIP enhances signaling by glycogen synthase kinase-33. Cancer Res 71: 1334-1343, 2011.

23. Fu Z, Kitagawa Y, Shen R, Shah R, Mehra R, Rhodes D, Keller PJ, Mizokami A, Dunn R, Chinnaiyan AM, et al: Metastasis suppressor gene Raf kinase inhibitor protein (RKIP) is a novel prognostic marker in prostate cancer. Prostate 66: 248-256, 2006.

24. Martinho O, Simões K, Longatto-Filho A, Jacob CE, Zilberstein B, Bresciani C, Gama-Rodrigues J, Cecconello I, Alves V and Reis RM: Absence of RKIP expression is an independent prognostic biomarker for gastric cancer patients. Oncol Rep 29: 690-696, 2013.

25. Song SP, Zhang SB, Li ZH, Zhou YS, Li B, Bian ZW, Liao QD and Zhang YD: Reduced expression of Raf kinase inhibitor protein correlates with poor prognosis in pancreatic cancer. Clin Transl Oncol 14: 848-852, 2012.

26. Afonso J, Longatto-Filho A, Martinho O, Lobo F, Amaro T, Reis RM and Santos LL: Low RKIP expression associates with poor prognosis in bladder cancer patients. Virchows Arch 462: 445-453, 2013

27. Martinho O, Granja S, Jaraquemada T, Caeiro C, Miranda-Gonçalves V, Honavar M, Costa P, Damasceno M, Rosner MR, Lopes JM and Reis RM: Downregulation of RKIP is associated with poor outcome and malignant progression in gliomas. PLoS One 7: e30769, 2012.

28. Guo W, Dong Z, Guo Y, Lin X, Chen Z, Kuang G and Yang Z: Aberrant methylation and loss expression of RKIP is associated with tumor progression and poor prognosis in gastric cardia adenocarcinoma. Clin Exp Metastasis 30: 265-275, 2013.

29. Al-Mulla F, Hagan S, Al-Ali W, Jacob SP, Behbehani AI, Bitar MS, Dallol A and Kolch W: Raf kinase inhibitor protein: Mechanism of loss of expression and association with genomic instability. J Clin Pathol 61: 524-529, 2008. 